\title{
Robotic mitral valve repair for degenerative posterior leaflet prolapse
}

\author{
Hoda Javadikasgari ${ }^{1}$, Rakesh M. Suri ${ }^{1}$, Bassman Tappuni ${ }^{1}$, Ashley M. Lowry ${ }^{2}$, Tomislav Mihaljevic ${ }^{1}$, \\ Stephanie Mick ${ }^{1}$, A. Marc Gillinov ${ }^{1}$ \\ ${ }^{1}$ Department of Thoracic and Cardiovascular Surgery, Heart and Vascular Institute, ${ }^{2}$ Quantitative Health Sciences, Cleveland Clinic, Cleveland, \\ Ohio, USA \\ Correspondence to: A. Marc Gillinov, MD. Department of Thoracic and Cardiovascular Surgery, Cleveland Clinic, 9500 Euclid Avenue, Desk J4-1, \\ Cleveland, OH 44195, USA. Email: gillinom@ccf.org.
}

\begin{abstract}
Background: Robotic mitral valve (MV) repair is the least invasive surgical approach to the $M V$ and provides unparalleled access to the valve. We sought to assess technical aspects and clinical outcomes of robotic MV repair for isolated posterior leaflet prolapse by examining the first 623 such cases performed in a tertiary care center.

Methods: We reviewed the first 623 patients (mean age $56 \pm 9.7$ years) with isolated posterior leaflet prolapse who underwent robotic primary MV repair from 01/2006 to 11/2013. All procedures were performed via right chest access with femoral perfusion for cardiopulmonary bypass.

Results: MV repair was attempted in all patients; 622 (99.8\%) underwent MV repair and only $1(0.2 \%)$ converted to replacement. After an initial attempt at robotic MV repair, 8 (1.3\%) patients were converted to sternotomy as a result of management of residual mitral regurgitation $(n=3)$, bleeding $(n=1)$, difficulties with surgical exposure $(n=2)$, aortic valve injury $(n=1)$, and aortic dissection $(n=1)$. Intraoperative postrepair echocardiography confirmed that all patients left the operating room with MR graded as mild or less, and pre-discharge echocardiography confirmed mild or less MR in 573 (99.1\%). There was no hospital death, sternal wound infection, or renal failure. Seven $(1.1 \%)$ patients suffered a stroke, $11(1.8 \%)$ patients underwent re-exploration for bleeding, and 111 (19\%) experienced new-onset atrial fibrillation. The mean intensive care unit length of stay and hospital length of stay were $29 \pm 17$ hours and $4.6 \pm 1.6$ days, respectively.

Conclusions: At a large tertiary care referral center, robotic MV repair for posterior prolapse is associated with zero mortality, infrequent operative morbidity, and near $100 \%$ successful repair. The combination of a patient selection algorithm and increased experience improved clinical outcomes and procedural efficiency.
\end{abstract}

Keywords: Mitral valve (MV); robotic; repair; prolapse

Submitted Dec 14, 2016. Accepted for publication Jan 04, 2017.

doi: 10.21037/acs.2017.01.07

View this article at: http://dx.doi.org/10.21037/acs.2017.01.07

\section{Introduction}

Robotic mitral valve (MV) repair was introduced in the 1990s to reproduce previous excellent results of conventional MV repair while approaching the valve through ports and small incisions on the right chest. Other advantages of robotic MV repair include reduced need for blood transfusions, shorter postoperative stay, quicker return to full activity, and superior cosmetic results (1-4).

The robotic MV repair program began at our center in 2006. Herein we report the results of our first 623 robotic cases of MV repair for isolated posterior leaflet prolapse. We sought to evaluate the early in-hospital safety and effectiveness of this technique.

\section{Methods}

\section{Patients}

From January 2006 to November 2013, 623 patients with isolated posterior prolapse underwent primary robotic $\mathrm{MV}$ repair at Cleveland Clinic. The mean age of patients was 


\begin{tabular}{|c|c|c|}
\hline Characteristic & $\mathrm{n}^{*}$ & $\begin{array}{l}\text { No. }(\%) \text { or } \\
\text { mean } \pm \text { SD }\end{array}$ \\
\hline \multicolumn{3}{|l|}{ Demographics } \\
\hline Age (years) & 623 & $56.2 \pm 9.7$ \\
\hline Male & 623 & $529(85 \%)$ \\
\hline Body mass index $\left(\mathrm{kg} / \mathrm{m}^{2}\right)$ & 620 & $26.3 \pm 3.8$ \\
\hline \multicolumn{3}{|l|}{ Symptoms } \\
\hline NYHA functional class & 546 & \\
\hline I & & $292(53 \%)$ \\
\hline II & & $220(40 \%)$ \\
\hline III & & $33(6 \%)$ \\
\hline IV & & $1(0.18 \%)$ \\
\hline Ejection fraction (\%) & 586 & $61 \pm 4.9$ \\
\hline \multicolumn{3}{|l|}{ Cardiac comorbidities } \\
\hline Atrial fibrillation & 623 & $50(8 \%)$ \\
\hline Prior myocardial infarction & 623 & $8(1.3 \%)$ \\
\hline Tricuspid regurgitation grade & 623 & \\
\hline None & & $462(74 \%)$ \\
\hline Mild & & $119(19 \%)$ \\
\hline Moderate & & $42(6.7 \%)$ \\
\hline Aortic regurgitation grade & 623 & \\
\hline None & & $590(95 \%)$ \\
\hline Mild & & 27 (4.3\%) \\
\hline Moderate & & $6(0.96 \%)$ \\
\hline \multicolumn{3}{|l|}{ Non-cardiac comorbidities } \\
\hline Carotid disease & 623 & $19(3 \%)$ \\
\hline Stroke & 623 & $10(1.6 \%)$ \\
\hline Peripheral arterial disease & 623 & $7(1.1 \%)$ \\
\hline Hypertension & 623 & $280(45 \%)$ \\
\hline Diabetes & 622 & $10(1.6 \%)$ \\
\hline COPD & 623 & $23(3.7 \%)$ \\
\hline
\end{tabular}

$56.2 \pm 9.7$ years and $529(85 \%)$ were male (Table 1$)$.

The data presented in this paper were derived from routine prospective data collection for quality and research by the Heart and Vascular Institute's Clinical Investigations group and were approved for use in research by the Cleveland Clinic Institutional Review Board, with patient consent waived.

\section{Perioperative screening}

At our center, the preoperative screening strategy includes coronary angiography or computed tomography (CT) angiography, transthoracic echocardiography (TTE) and CT scanning of the chest, abdomen, and pelvis for all patients. The robotic approach is not used if coronary artery bypass grafting is required. Intraoperative screening includes two-dimensional and three-dimensional (3D) transesophageal echocardiography (TEE). We have constructed our patient selection algorithm based upon different imaging studies obtained before the proposed robotic MV surgery (Figure 1).

\section{Surgical technique}

Standard robotic $M V$ repair was attempted in all patients (3-5). Access ports were placed through the right chest, and the femoral artery and right internal jugular and femoral veins were cannulated for cardiopulmonary bypass. The ascending aorta was occluded either by an endoaortic balloon $(\mathrm{n}=156,25 \%)$ or a Chitwood transthoracic clamp $(\mathrm{n}=467,75 \%)$. The heart was then arrested with $1 \mathrm{~L}$ of Buckberg cardioplegia with repeated doses every 15-20 minutes, or with a single dose of del Nido cardioplegia.

Out of 623 patients, MV repair techniques included triangular/quadrangular posterior leaflet resection (79\%), folding valvuloplasty (8\%), sliding annuloplasty (35\%), cleft closure $(30 \%)$, and insertion of polytetrafluoroethylene (PTFE) chords (21\%) (Table 2). Concomitant atrial fibrillation procedures included the Cryo-Maze procedure (box lesion around the pulmonary veins and connecting lesion between the MV annulus and this box lesion) and left atrial appendage closure with two-layer 3-0 PTFE sutures (Table 2).

\section{Outcomes}

The technical performance, effectiveness, and safety of robotic posterior $M V$ repair were assessed by evaluating 


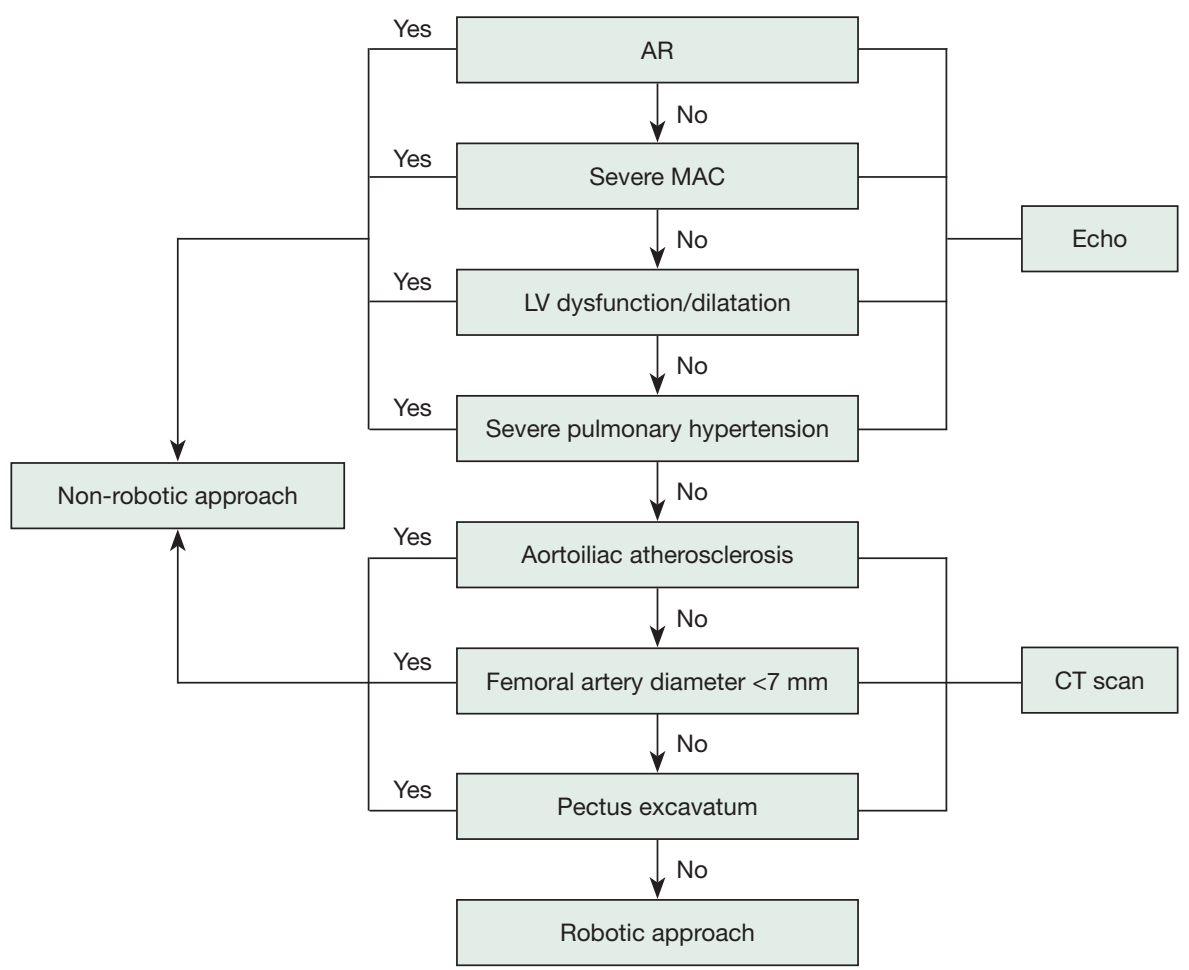

Figure 1 Algorithm to select candidates for robotically assisted mitral valve surgery. AR, aortic regurgitation; MAC, mitral annular calcification; LV, left ventricle; CT scan, computed tomography scan.

\begin{tabular}{lll} 
Table 2 Operative details & & \\
\hline Detail & $\mathrm{n}^{*}$ & No. (\%) \\
\hline $\begin{array}{l}\text { Type of posterior leaflet repair } \\
\text { Leaflet resection }\end{array}$ & 623 & $494(79 \%)$ \\
$\quad$ Triangular & 494 & $323(65 \%)$ \\
$\quad$ Folding valvuloplasty & 323 & $50(15 \%)$ \\
$\quad$ Quadrangular & 494 & $171(35 \%)$ \\
$\quad$ Sliding annuloplasty & 171 & $171(100 \%)$ \\
Posterior leaflet cleft closure & 623 & $185(30 \%)$ \\
PTFE artificial chordae & 623 & $128(21 \%)$ \\
Annuloplasty & 623 & $623(100 \%)$ \\
\hline $\begin{array}{l}\text { Concomitant procedures } \\
\text { Ablation for atrial fibrillation }\end{array}$ & 623 & $41(6.6 \%)$ \\
\hline PFO/ASD closure & 623 & $56(9.0 \%)$ \\
\hline * patients with applicable data. MR, mitral regurgitation; \\
$\begin{array}{l}\text { PFO/ASD, patent foramen ovale/atrial septal } \\
\text { polytetrafluoroethylene. }\end{array}$
\end{tabular}

operative times, intraoperative TEE, and in-hospital mortality and morbidity as defined for the Society of Thoracic Surgeons (STS) National Cardiac Database (see http://www.sts.org/sites/default/files/documents/STSAdult CVDataSpecificationsV2_81.pdf). In our study, conversion was defined as changing from the robotic approach to a conventional incision at the time of surgery.

\section{Data analysis and presentation}

Continuous variables are summarized as mean \pm standard deviation, and categorical variables are summarized as frequencies and percentages. All analyses were performed using SAS statistical software (SAS version 9.4; SAS Institute, Cary, NC, USA).

\section{Results}

Preoperatively, all patients had significant mitral regurgitation and 34 (6.2\%) had New York heart association class III/IV. Table 1 summarizes the baseline characteristics 


\begin{tabular}{|ll}
\hline \multicolumn{2}{l}{ Table 3 Postoperative in-hospital complications ( $\mathrm{n}=623)$} \\
\hline Variable & No. $(\%)$ \\
\hline Death & 0 \\
\hline Stroke & $7(1.1 \%)$ \\
\hline Sternal wound infection & $0(0 \%)$ \\
\hline New-onset atrial fibrillation* & $111(19 \%)$ \\
\hline Reoperation for bleeding & $11(1.8 \%)$ \\
\hline Prolonged ventilation (>24 hours) & $9(1.4 \%)$ \\
\hline Renal failure & 0 \\
\hline Aortic dissection & $1(0.2 \%)$ \\
\hline ICD implantation & $3(0.5 \%)$ \\
\hline
\end{tabular}

${ }^{*}, n=573$, patients with preoperative atrial fibrillation were excluded from denominator. ICD, implantable cardioverter-defibrillator.

of the patients.

\section{Technical performance and effectiveness}

Out of 623 patients with intent to repair, 622 (99.8\%) underwent $M V$ repair and only one $(0.16 \%)$ converted to replacement. After an initial attempt at robotic MV repair, $8(1.3 \%)$ patients were converted to sternotomy as a result of management of residual MR ( $n=3)$, bleeding $(n=1)$, difficulties with surgical exposure $(n=2)$, aortic valve injury $(\mathrm{n}=1)$, and aortic dissection $(\mathrm{n}=1)$. The mean myocardial ischemia and cardiopulmonary bypass time were $80.8 \pm 22.7$ and $116 \pm 30.9$ minutes, respectively.

Intraoperative post-repair echocardiography confirmed that all patients left the operating room with MR graded as mild or less, and pre-discharge echocardiography confirmed mild or less MR in 573 (99.1\%).

\section{Safety}

There was no hospital death, sternal wound infection, renal failure, or complication of peripheral cannulation. Seven $(1.1 \%)$ patients suffered a stroke, confirmed by both clinical examination and imaging (CT scan or magnetic resonance imaging), 11 (1.8\%) patients underwent re-exploration for bleeding, and $111(19 \%)$ experienced new-onset atrial fibrillation (Table 3). The mean intensive care unit length of stay and hospital length of stay were $28.8 \pm 17.4$ hours and $4.9 \pm 1.6$ days, respectively.

\section{Discussion}

\section{Key findings}

This study demonstrates that robotic MV repair for isolated posterior leaflet prolapse is safe and effective with zero mortality, low risk of morbidity, and high procedural success. MV repair was achieved in almost $100 \%$ of patients, and $99.1 \%$ of these had mild or less MR at discharge. Technical and procedural improvements were achieved by having dedicated surgeons who were highly experienced in MV repair perform the operations, and applying the screening algorithm.

\section{Technical performance and effectiveness}

Modified cardiopulmonary bypass techniques and new instrumentation developed in the mid-1990s facilitated minimally invasive MV surgery. However, difficulties with using two-dimensional vision and challenges with the application of long-shafted instruments limited its adoption. The development of the da Vinci ${ }^{\mathrm{TM}}$ System (Intuitive Surgical, Inc., Sunnyvale, CA, USA) with telemanipulation and three-dimensional (3D) visualization augmented the surgeon's ability to perform minimally invasive MV surgery. Despite multiple studies confirming excellent results with robotic MV repair, concerns regarding efficacy and safety of this approach have slowed adoption of this technology.

Greater complexity of the robotic approach is attributable to port placement, management of cardiopulmonary bypass and myocardial protection, and also presentation of a learning curve which results in longer operative times compared to conventional approaches. However, these differences are not associated with clinical sequelae (3). Furthermore, increased surgeon experience resulted in identifying streamlined techniques, and modified patient selection criteria also improved outcomes over time, reducing the number of conversions and the incidence of perioperative stroke $(6,7)$. Furthermore, long-term results of robotic mitral repair demonstrate that survival and durability are similar to those obtained with non-robotic approaches $(3,8,9)$.

\section{Safety}

Zero in-hospital mortality and low rates of morbidity in our study reaffirm the safety demonstrated in previous large series (8-11). Compared to non-robotic approaches, 
robotic MV surgery has been associated with a lower inhospital mortality, reduced blood loss, lower risk of wound infections, shorter postoperative length of stay, quicker return to normal activity, and superior cosmetic results (1214). Furthermore, the quality of valve repair was similar in propensity-matched cohorts to that performed through conventional approaches (12).

Concern over the higher risk of stroke with less invasive MV surgery that involved femoral artery perfusion remains an important issue (15). However, we believe that retrograde embolization of atheromatous material, as well as embolization of air, debris from the left atrium, and clamping an atherosclerotic aorta are the likely sources of emboli. Preoperative CT scanning identifies patients at risk and axillary artery cannulation for cardiopulmonary bypass enables safer perfusion strategies in such patients (16).

\section{Limitations}

This is a single-institution study with outcomes limited to the hospital course. We did not analyze the cost and resource utilization; however, previous studies demonstrate that the total hospital cost associated with the use of robotic MV surgery has now become similar to that for conventional approaches $(17,18)$.

\section{Conclusions}

Robotic MV repair for correction of posterior leaflet prolapse is safe and effective. Ongoing development of new techniques will further enhance the efficacy and outcomes.

\section{Acknowledgements}

None.

\section{Footnote}

Conflicts of Interest: Dr. Gillinov is a consultant for CryoCath Technologies, Edwards Lifesciences, Medtronic, St. Jude Medical, Abbott Laboratories, and Atricure. He receives research funding from St. Jude Medical and Tendyne. Other authors have no conflicts of interest to declare.

Ethical Statement: The study was approved by the Cleveland Clinic Institutional Review Board, with patient consent waived.

\section{References}

1. Mohr FW, Falk V, Diegeler A, et al. Computer-enhanced "robotic" cardiac surgery: experience in 148 patients. $\mathrm{J}$ Thorac Cardiovasc Surg 2001;121:842-53.

2. Chitwood WR Jr, Rodriguez E, Chu MW, et al. Robotic mitral valve repairs in 300 patients: a single-center experience. J Thorac Cardiovasc Surg 2008;136:436-41.

3. Mihaljevic T, Jarrett CM, Gillinov AM, et al. Robotic repair of posterior mitral valve prolapse versus conventional approaches: potential realized. J Thorac Cardiovasc Surg 2011;141:72-80.e1-4.

4. Suri RM, Dearani JA, Mihaljevic T, et al. Mitral valve repair using robotic technology: Safe, effective, and durable. J Thorac Cardiovasc Surg 2016;151:1450-4.

5. Javadikasgari H, Suri RM, Mihaljevic T, et al. Technical aspects of robotic posterior mitral valve leaflet repair. Ann Cardiothorac Surg 2016;5:577-81.

6. Mihaljevic T, Jarrett CM, Gillinov AM, et al. A novel running annuloplasty suture technique for robotically assisted mitral valve repair. J Thorac Cardiovasc Surg 2010;139:1343-4.

7. George KM, Mihaljevic T, Gillinov AM. Triangular resection for posterior mitral prolapse: rationale for a simpler repair. J Heart Valve Dis 2009;18:119-21.

8. Suri RM, Taggarse A, Burkhart HM, et al. Robotic Mitral Valve Repair for Simple and Complex Degenerative Disease: Midterm Clinical and Echocardiographic Quality Outcomes. Circulation 2015;132:1961-8.

9. Murphy DA, Moss E, Binongo J, et al. The Expanding Role of Endoscopic Robotics in Mitral Valve Surgery: 1,257 Consecutive Procedures. Ann Thorac Surg 2015;100:1675-81; discussion 1681-2.

10. Ramzy D, Trento A, Cheng W, et al. Three hundred robotic-assisted mitral valve repairs: the Cedars-Sinai experience. J Thorac Cardiovasc Surg 2014;147:228-35.

11. Nifong LW, Rodriguez E, Chitwood WR Jr. 540 consecutive robotic mitral valve repairs including concomitant atrial fibrillation cryoablation. Ann Thorac Surg 2012;94:38-42; discussion 43.

12. Mihaljevic T, Jarrett CM, Gillinov AM, et al. Robotic repair of posterior mitral valve prolapse versus conventional approaches: potential realized. J Thorac Cardiovasc Surg 2011;141:72-80.e1-4.

13. Suri RM, Burkhart HM, Daly RC, et al. Robotic mitral valve repair for all prolapse subsets using techniques identical to open valvuloplasty: establishing the 
benchmark against which percutaneous interventions should be judged. J Thorac Cardiovasc Surg 2011;142:970-9.

14. Paul S, Isaacs AJ, Jalbert J, et al. A population-based analysis of robotic-assisted mitral valve repair. Ann Thorac Surg 2015;99:1546-53.

15. Gammie JS, Zhao Y, Peterson ED, et al. J. Maxwell Chamberlain Memorial Paper for adult cardiac surgery. Less-invasive mitral valve operations: trends and outcomes from the Society of Thoracic Surgeons Adult Cardiac Surgery Database. Ann Thorac Surg 2010;90:1401-8,

Cite this article as: Javadikasgari H, Suri RM, Tappuni B, Lowry AM, Mihaljevic T, Mick S, Gillinov AM. Robotic mitral valve repair for degenerative posterior leaflet prolapse. Ann Cardiothorac Surg 2017;6(1):27-32. doi: 10.21037/ acs.2017.01.07 1410.e1; discussion 1408-10.

16. Sabik JF, Lytle BW, McCarthy PM, et al. Axillary artery: an alternative site of arterial cannulation for patients with extensive aortic and peripheral vascular disease. J Thorac Cardiovasc Surg 1995;109:885-90; discussion 890-1.

17. Mihaljevic T, Koprivanac M, Kelava M, et al. Value of robotically assisted surgery for mitral valve disease. JAMA Surg 2014;149:679-86.

18. Suri RM, Thompson JE, Burkhart HM, et al. Improving affordability through innovation in the surgical treatment of mitral valve disease. Mayo Clin Proc 2013;88:1075-84. 